GEOCHRONOMETRIA 48 (2021): 402-414

DOI 10.2478/geochr-2020-0003

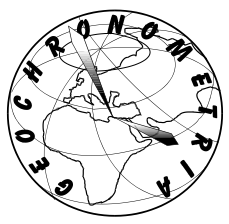

Conference Proceedings of the $5^{\text {th }}$ Asia Pacific Luminescence and Electron Spin Resonance Dating Conference October $15^{\text {th }}-17^{\text {th }}$, 2018, Beijing, China

Guest Editor: Grzegorz Adamiec

\title{
CW-OSL, LM-OSL AND TL DATING OF BRICKS FROM KARAKORUM, MONGOLIA: INSIGHTS FROM TL SPECTRA
}

\author{
SARAN SOLONGO ${ }^{1}$, SARAN TENGIS ${ }^{1}$, GÜNTHER A. WAGNER ${ }^{2}$ and HANS-GEORG HÜTTEL ${ }^{3}$ \\ ${ }^{I}$ Institute of Physics and Technology, Mongolian Academy of Sciences, 13330 Ulaanbaatar, Mongolia \\ ${ }^{2}$ Geographisches Institut, Universität Heidelberg, Heidelberg 69120, Germany \\ ${ }^{3}$ Komission für Allgemeine und Vergleichende Archäologie, Bonn, Germany
}

Received 15 February 2019

Accepted 7 October 2019

\begin{abstract}
In this study, we present results of luminescence dating using CW-OSL, LM-OSL and TL on heated quartz from the archaeological and historical site in Karakorum - the ancient capital of Mongolia, to test their convergence with the age control in the form of the Karakorum inscription 1346. The TL spectra conducted on quartz from red and grey coloured bricks appeared to be characteristic of the technological origin. Quartz TL from red bricks showed a UV emission band at $\sim 360 \mathrm{~nm}$ and a strong fast OSL component dominated signal. In contrast, blue emission detected in the TL spectra of grey coloured bricks, resulting possibly in the medium component dominated OSL signal.

Finally, OSL and TL results gave dates from $1180 \pm 70$ AD to $1360 \pm 70$ consistent with the expected ages.
\end{abstract}

Keywords: TL emission spectra, OSL, LM-OSL, TL-SAR, quartz, red and grey bricks.

\section{INTRODUCTION}

Quartz $\left(\mathrm{SiO}_{2}\right)$ is a natural dosimeter used in retrospective dosimetry, for archaeological and geological dating. The luminescence properties of natural quartz depend on the point defects contained within the crystal, which may reflect specific conditions during silica formation and its post-growth treatments. The detailed thermoluminescence (TL) emission spectra of a wide variety of quartz material were reported by Rink et al. (1993) who concluded that the colour of the TL emission is indicative of the provenance, growth method and thermal history of the materi-

Corresponding author: S. Solongo

e-mail: sarans@mas.ac.mn al. For example, they observed that granitic quartz could have various emissions at $360-380 \mathrm{~nm}, 420-470 \mathrm{~nm}$ and at $630 \mathrm{~nm}$. A broad TL emission band centred at 560-580 $\mathrm{nm}$ was observed only in natural quartz of hydrothermal origin and material of volcanic origin is usually dominated by red emission. Generally three TL emission bands: UV violet (360-440 nm), blue (around $450 \mathrm{~nm}$ ) and red $(650 \mathrm{~nm})$ have been observed in the TL emission spectra of natural quartz (Krbetscheck et al., 1997) resulting in $\mathrm{TL}$ peaks, namely at 110,220 and $325^{\circ} \mathrm{C}$; the $325^{\circ} \mathrm{C}$ peak is used in TL dosimetry and dating.

While a wide range of emission wavelengths are available for analysis in TL dosimetry, the choice of optically stimulated luminescence (OSL) methods is limited due to the need to use excitation wavelengths in the blue/green spectral range. Most commonly, the OSL signal is observed using optical filters that pass wave- 
lengths centred on $340 \mathrm{~nm}$ during optical stimulation at $470 \mathrm{~nm}$ (Bøtter-Jensen et al., 2010); (Wintle and Adamiec, 2017). This is advantageous since using optical excitation at $647 \mathrm{~nm}$, (Huntley et al., 1991) found the OSL emission of natural quartz to be centred at $\sim 365 \mathrm{~nm}$, with only weak emission between 400 and $500 \mathrm{~nm}$.

However, the luminescence detected in this region shows unusual characteristics, especially after hightemperature annealing $\left(0-1200^{\circ} \mathrm{C}\right)$, whereby particular enhancement in the luminescence sensitivity occurs between the phase transition temperatures 573 and $870^{\circ} \mathrm{C}$ (Bøtter-Jensen et al., 1995). In a more detailed study, Poolton et al. (2000) attempted to correlate such OSL behaviour of material that had undergone successive annealing treatments, with changes in the defect structures and populations, as monitored by EPR. They tentatively concluded that oxygen vacancy ( $\left.\mathrm{E}^{\prime}\right)$ centres act as non-radiative recombination centres, competing with the trap responsible for the UV emission: such $\mathrm{E}^{\prime}$ centres are annealed out of the samples at temperatures in the range $500-700^{\circ} \mathrm{C}$, explaining the OSL sensitivity increase. The $\mathrm{UV}$ emission is attributed to the $\left[\mathrm{AlO}_{4}\right]^{0}$ centres (Martini et al., 1995); and thermal treatment has already been reported to strongly enhance the UV emission (Martini et al., 2012). Studies on well-defined relationships between the mentioned luminescence emissions and specific defects in quartz are still ongoing.

In this study, luminescence properties of heated quartz from the archaeological site at Karakorum (Mongolia) will be investigated in terms of their thermoluminescence spectra. Previously, bricks from historical buildings in Mongolia were studied by optically stimulated luminescence (Solongo et al., 2006a, 2006b, 2006c) in order to extract information about the chronology of the brick production at the Karakorum. The known historical facts about the chronology of some parts of the historical buildings in the Karakorum allowed testing the OSL to architectural ceramics, thus ensuring an age underestimation previously obtained for some bricks. The bricks were produced in the "Mantou" type kilns under oxidising/ reducing atmosphere and were subjected to different thermal treatment performed during brick production in the past. By the results presented in this article, we want to examine how these thermal treatments affect the thermoluminescence spectra of quartz and the dose evaluation using various SAR protocols.

\section{EXPERIMENTAL}

\section{Site and samples}

The brick samples used in this study were collected at the archaeological site Karakorum $\left(47^{\circ} 12^{\prime} \mathrm{N} / 102^{\circ} 50^{\prime} \mathrm{E}\right.$; 1461-1462 m a.s.l.) located in Orkhon Valley, Mongolia. This site assumed major importance as the medieval capital of the Great Mongolian Empire and as one of the most important cities in the history of the Silk Road. Karakorum (Qara Qorum) founded in 1220 became a walled urban settlement under Chinggis Khaan's son Ögedei Khan in 1235. "The palace district" was first identified in 1948-1949 by a Russian-Mongolian archaeological team led by Sergei V. Kiselev (Kiselev et al., 1965). The Mongolian-German Karakorum Expedition (MDKE) conducted by the German Archaeological Institute (DAI) and the Mongolian Academy of Sciences (MAS) in the old Mongolian capital has radically revised the conventional image of Karakorum (Hüttel and Erdenebat, 2011). According to the inscriptions, the Wanan palace of Ögodei Khan and some temples built at the same time, among them a monumental Buddhist stupa temple, the "pavilion/temple of the origin of the Yüan", are held as the oldest buildings of the city. They were built in 1235 at the same time as the city walls. While the palace was completed within a year in the early part of 1236 , the great Buddhist stupa temple was only finalised in 1256. It is known that the first restoration of the temple took place in 1311, and the second one between 1342 and 1346 (Hüttel and Erdenebat, 2011).

About fourteen "Mantou" type kilns with round walled fire pits and fire canals were discovered, nine of which were almost entirely intact (Hüttel and Erdenebat, 2011); it is evident that that numerous architectural ceramics, including roof tiles, bricks and Buddhist figurines come from these factories. These bricks were initially classified based on their colour, which is indicative of the provenance, use of oxidising and reducing atmosphere and thermal history of the material. In most kilns, carbon monoxide serves as the primary reducing agent, but in some traditions, hydrogen (a potent reducing gas) may have been generated towards the end of the firing through the introduction of water to the firebox or the kilnchamber (Rose Kerr, 2004). Red coloured bricks were produced in an oxidising atmosphere, while grey coloured bricks were produced using conventional "airstarved fuel" reduction or the generation of water gas. Firing temperatures in the "Mantou" type kilns ranged in the interval $800-1000^{\circ} \mathrm{C}$ (Rose Kerr, 2004).

The bricks from the Karakorum were previously subjected to CW-OSL measurements; quartz from grey coloured bricks, however, gave significant dose/age underestimations (Solongo et al., 2006a). The main reason for this was that the ratio of fast to medium components was too low and $\mathrm{D}_{\mathrm{e}}$ 's with the highest fast to medium ratio were considered; in addition, we performed post-IR-OSL (Banerjee et al., 2001), leading to better dose estimates. That led to the conclusion that only red coloured bricks were suitable for blue-stimulated CW-OSL measurements.

\section{Sample preparation and measuring equipment}

The environmental radiation dose rates were measured using high-resolution $\gamma$-spectrometry applied to the external layer of the sample to determine $\mathrm{K}, \mathrm{U}$ and $\mathrm{Th}$ concentrations. In-situ water content measured shortly after sampling was taken into account. The contribution 
from cosmic radiation to the dose rate was calculated following Prescott and Hutton (1994), assuming an uncertainty of $5 \%$. The radionuclide concentrations were converted to dose rate data using the conversion factors from Guerin et al. (2011). Table 1 summarises the sample description and dose rate data.

For luminescence procedures, the external layer of the ceramic fragments was removed; the obtained cores were carefully crushed and sieved. All crushed material was subjected to $15 \% \mathrm{H}_{2} \mathrm{O}_{2}, 30 \% \mathrm{H}_{2} \mathrm{O}_{2}$ to remove organic material, to $10 \% \mathrm{HCl}$ to dissolve carbonate minerals, prior to density separation using a heavy liquid and separated by $2.62 \mathrm{~g} \mathrm{~cm}^{-3}$ and $2.74 \mathrm{~g} \mathrm{~cm}^{-3}$ to obtain quartz fractions. For quartz, grains were etched with $40 \%$ hydrofluoric acid (HF) for $40 \mathrm{~min}$. to remove the alpha irradiated outer rinds and $\mathrm{HCl}$ to eliminate the possible formation of fluorosilicates. For OSL and TL measurements 90-120 $\mu \mathrm{m}$ coarse grains were deposited onto disc using $1 \mathrm{~mm}$ and $2 \mathrm{~mm}$ spot, while for TL spectra measurements $8 \mathrm{~mm}$ aliquots were used.

Spectral measurements were carried out in MPI Heidelberg using the TL/OSL-Spectrometer described by Rieser et al. (1999). Here a Czerny-Turner flat field spectrograph was equipped with a grating of 150 lines $\mathrm{mm}^{-1}$ for the measurements, with the entrance slit of spectrograph being set to $0.5 \mathrm{~mm}$. The detector used was a liquid nitrogen cooled CCD array (Princeton Instruments), which had a size $1100 \times 330$ pixel. In order to cut the intense red/IR thermal emission at higher temperatures, the heat-absorbing filters were used.
All OSL measurements were performed using an automated Risø TL/OSL-DA-15 reader, equipped with blue light-emitting diodes $\left(470 \pm 30 \mathrm{~nm}, 50 \mathrm{~mW} \mathrm{~cm}^{-2}\right)$ for stimulating the quartz, a Thorn-EMI 9235 photomultiplier combined with three $2.5 \mathrm{~mm}$ U-340 Hoya filters (290$370 \mathrm{~nm}$ ) for OSL signal detection. Laboratory irradiation was undertaken using a calibrated ${ }^{90} \mathrm{Sr} r{ }^{90} \mathrm{Y}$ beta source delivering $(2.72 \pm 0.2 \mathrm{~Gy} / \mathrm{min})$ to coarse grain aliquot. LMOSL measurements were carried out by continuously ramping the power from zero to maximum $(90 \%$ of power), over a period of typically $3000 \mathrm{~s}$. For TL measurements, the TL glow curves $\left(180-460^{\circ} \mathrm{C} ; 5^{\circ} \mathrm{C} / \mathrm{s}\right)$ were recorded using "D410 transmission filter" $(410 \pm 30 \mathrm{~nm})$ for TL signal detection. The dose $D_{e}$ was determined using SAR (Table 2) procedure (Murray and Wintle, 2003), which employed CW-OSL, LM-OSL and TL measurements.

\section{RESULTS AND DISCUSSION}

\section{Quartz TL emission spectra}

For the measurement of TL emission spectra samples were irradiated artificially with 50 Gy using a $90 \mathrm{Sr}$ $\beta$-source and stored for four weeks at room temperature. Because luminescence of natural quartz is usually weak, some samples were irradiated with $100 \mathrm{~Gy}$. The measurements were performed using a heating rate of $5^{\circ} \mathrm{C} / \mathrm{s}$, a spectral range of 300-1200 nm, and a temperature range of $20-500^{\circ} \mathrm{C}$.

Table 1. Fragments of bricks for luminescence dating and concentration of radionuclides measured by high-resolution gamma-spectrometry.

\begin{tabular}{lccccc}
\hline Sample Description & $\begin{array}{c}{ }^{232} \mathrm{Th} \\
(\mathbf{p p m})\end{array}$ & $\begin{array}{c}{ }^{235 \mathrm{U}} \\
(\mathbf{p p m})\end{array}$ & $\begin{array}{c}{ }^{40} \mathrm{~K} \\
(\%)\end{array}$ & $\begin{array}{c}\beta \text { (mGy/a), } \\
\beta \text { counter }\end{array}$ & $\begin{array}{c}\mathrm{V} \\
(\mathrm{mGy} / \mathrm{a})\end{array}$ \\
\hline K02/01, brick, Great Hall floor, red colored & $12.79 \pm 0.22$ & $3.43 \pm 0.09$ & $2.77 \pm 0.015$ & $3.16 \pm 0.07$ & $1.73 \pm 0.02$ \\
\hline HD12B, brick, Great Hall red colored & $14.88 \pm 0.32$ & $4.26 \pm 0.18$ & $2.77 \pm 0.10$ & $3.02 \pm 0.015$ & $1.86 \pm 0.07$ \\
\hline HD3, brick, red-colored & $13.45 \pm 0.29$ & $3.98 \pm 0.12$ & $2.68 \pm 0.09$ & $2.93 \pm 0.15$ & $1.74 \pm 0.09$ \\
\hline HD3-1, brick, red-colored & $13.73 \pm 0.26$ & $4.52 \pm 0.12$ & $2.59 \pm 0.08$ & $2.93 \pm 0.15$ & $1.78 \pm 0.09$ \\
\hline B288B,brick, red-colored, basement, manufacturing & $14.66 \pm 0.28$ & $4.23 \pm 0.09$ & $2.87 \pm 0.085$ & $3.03 \pm 0.15$ & $1.84 \pm 0.080$ \\
\hline K02/02, brick, Buddhist ground, grey colored & $12.86 \pm 0.022$ & $3.71 \pm 0.09$ & $2.79 \pm 0.08$ & $2.92 \pm 0.15$ & $1.60 \pm 0.04$ \\
\hline K02/08 wallbrick, Stupa basement, grey colored & $13.87 \pm 0.17$ & $4.05 \pm 0.07$ & $2.70 \pm 0.05$ & $2.99 \pm 0.15$ & $1.81 \pm 0.04$ \\
\hline HD2-57, grey colored 3-B2027, P202, format 45mm & $13.68 \pm 0.28$ & $4.24 \pm 0.13$ & $2.74 \pm 0.09$ & $2.82 \pm 0.14$ & $1.79 \pm 0.09$ \\
\hline K36, brick, small kiln, grey colored & $12.97 \pm 0.20$ & $3.49 \pm 0.08$ & $2.85 \pm 0.06$ & $2.972 \pm 0.15$ & $1.77 \pm 0.02$ \\
\hline
\end{tabular}

Table 2. SAR procedure using CW-OSL, LM-OSL, TL used in this study.

\begin{tabular}{|c|c|c|c|}
\hline \multicolumn{2}{|c|}{ Step CW-OSL } & \multirow{2}{*}{$\begin{array}{l}\text { LM-OSL } \\
\text { Give dose }(3.0 ; 4.7 ; 6.5 ; 0 ; 3.0 \mathrm{~Gy})\end{array}$} & \multirow{2}{*}{$\begin{array}{l}\text { TL } \\
\text { Give dose }(1.59 ; 3.59 ; 5.19 ; 0 ; 1.59 \mathrm{~Gy})\end{array}$} \\
\hline 1 & Give dose $(3.0 ; 4.7 ; 6.5 ; 0 ; 3.0 \mathrm{~Gy})$ & & \\
\hline$\underline{2}$ & Preheat $\left(220^{\circ} \mathrm{C}\right.$ for $\left.10 \mathrm{~s}\right)$ & Preheat $\left(220^{\circ} \mathrm{C}\right.$ for $\left.10 \mathrm{~s}\right)$ & Preheat $\left(180^{\circ} \mathrm{C}\right.$ for $10 \mathrm{~s}$ at $\left.5^{\circ} \mathrm{C} / \mathrm{s}\right)$ \\
\hline 3 & CW-OSL for $20 \mathrm{~s}$ at $125^{\circ} \mathrm{C}, L_{x}$ & LM-OSL for $500 \mathrm{~s}$ (or $3000 \mathrm{~s}$ ) at $125^{\circ} \mathrm{C}, L_{x}$ & $\mathrm{TL} 495^{\circ} \mathrm{C}, L_{x}$ \\
\hline 4 & Test dose (0.18Gy /or 0.64Gy) & Test dose (e.g. $0.26 \mathrm{~Gy})$ & Test dose (e.g. $0.39 \mathrm{~Gy})$ \\
\hline 5 & Cutheat to $220^{\circ} \mathrm{C}$ & Cutheat to $220^{\circ} \mathrm{C}$ & Preheat $\left(180^{\circ} \mathrm{C}\right.$ for $10 \mathrm{~s}$ at $\left.5^{\circ} \mathrm{C} / \mathrm{s}\right)$ \\
\hline 6 & $\mathrm{CW}-\mathrm{OSL}$ for $20 \mathrm{~s}$ at $125^{\circ} \mathrm{C}, T_{x}$ & LM-OSL for $500 \mathrm{~s}(3000 \mathrm{~s})$ at $125^{\circ} \mathrm{C}, T_{x}$ & $\mathrm{TL} 495^{\circ} \mathrm{C}, 5^{\circ} \mathrm{C} / \mathrm{s}, T_{x}$ \\
\hline 7 & & \multicolumn{2}{|c|}{ Seq. LM-OSL for $500 \mathrm{~s}(3000 \mathrm{~s})$ at $125^{\circ} \mathrm{C}(\times 5)$} \\
\hline 8 & Return to step 1 & Return to step 1 & Return to step 1 \\
\hline
\end{tabular}


Fig. 1a, 1b show the representative TL contour plot obtained for the natural laboratory irradiated quartz samples HD3 (red brick) and HD2-57 (grey brick). Over the entire investigated temperature range, the spectrum of the detected glow peaks is dominated by a blue emission. Two TL peaks are clearly detected around $225^{\circ} \mathrm{C}$ and $350^{\circ} \mathrm{C}$, respectively.

Fig. 2a, 2b shows TL emission spectra plotted vs the wavelength. For quartz HD3, the emission band peak had maxima at $\sim 360$, and $440 \mathrm{~nm}$, in agreement with the wavelength peaks presented in summary by (Krbetscheck et al., 1997). For this sample, for the temperature range of 75 to $175^{\circ} \mathrm{C}$, both the UV emission band peaking at $\sim 366$ $\mathrm{nm}$ and the blue emission band peaking at $440-460 \mathrm{~nm}$ $(\sim 2.8 \mathrm{eV})$ increased in intensity. The UV emission band is still observed in the range $200-275^{\circ} \mathrm{C}$, but disappears at $300^{\circ} \mathrm{C}$. In contrast, the blue emission at $470 \mathrm{~nm}(2.6-$ $2.5 \mathrm{eV}$ ) emission increases for $200-275^{\circ} \mathrm{C}$.

In contrast, for quartz HD2-57 the UV emission band is missing. The emission had maxima at $\sim 478 \mathrm{~nm}$ and a low-intensity orange-red band at $\sim 600 \mathrm{~nm}$. We observed an increase in the intensity of blue emission bands over a temperature range of 125 to $175^{\circ} \mathrm{C}$, but this tends to decrease with the further rise in temperature from 225 to $350^{\circ} \mathrm{C}$. The intense high-temperature peak at around $\sim 800 \mathrm{~nm}$ observed in both samples may be inherited from the thermal history.

The comparison of the TL emission results is a strong indication that annealing in the past has taken place at different temperatures. Similar treatments have been already described in the literature. Previously, (BøtterJensen et al., 1995) showed that a high-temperature an- (a)
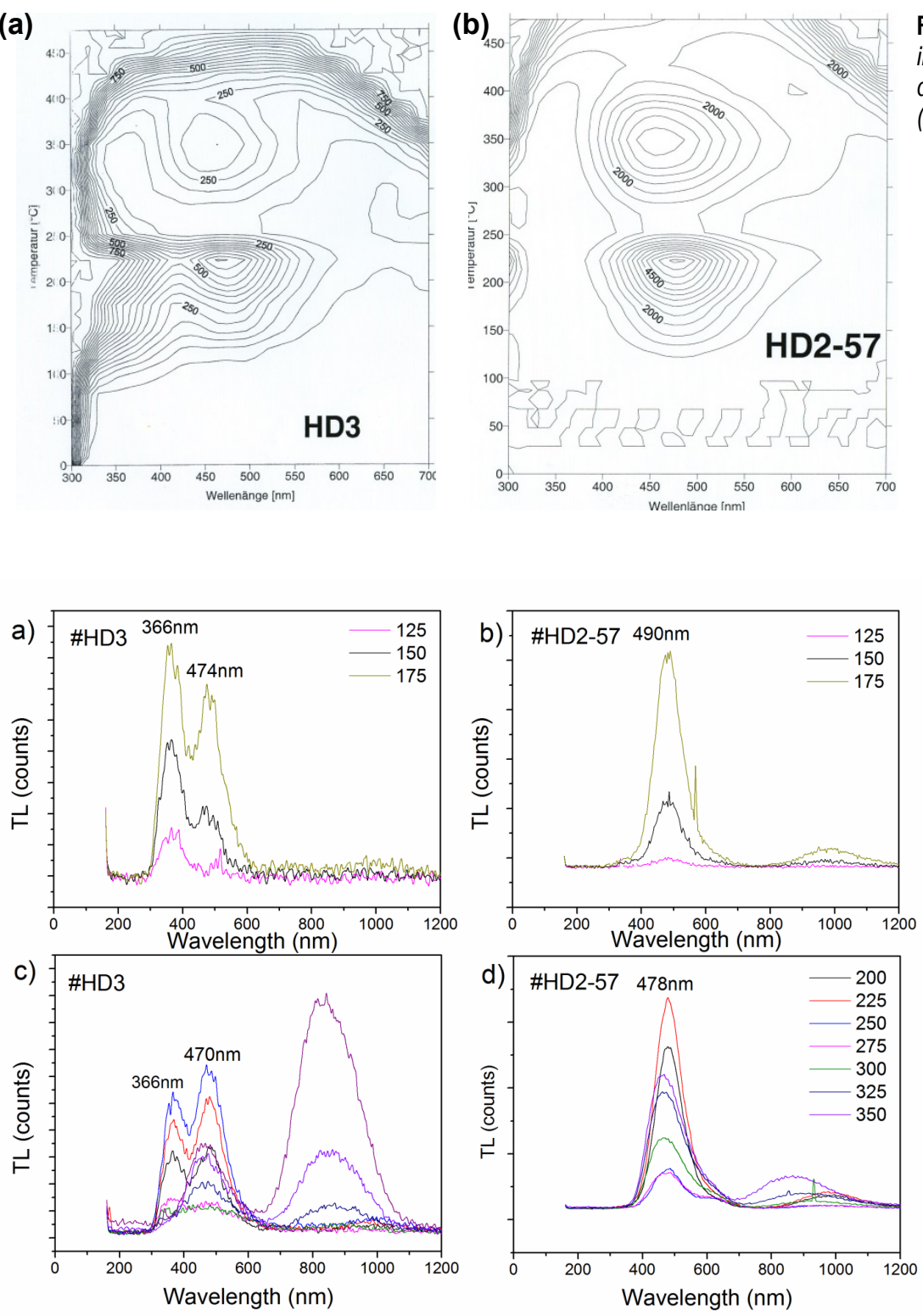

Fig. 1. TL contour map recorded after laboratory $\beta$ irradiation and storage for 4 weeks. (a) heated quartz samples HD3 (red coloured brick), and (b)HD2-57 (grey coloured brick).
Fig. 2. $T L$ emission spectra for heated quartz (a, c) HD3 and (b, d) HD2-57. Deconvolution into Gaussian components of the thermoluminescence emission spectra of HD3 showed a broad UV emission band peaking at $366 \mathrm{~nm}$, and the blue emission band peaking at $474 \mathrm{~nm}$. HD2-57 showed typical for quartz blue emission bands peaking at $470 \mathrm{~nm}$ for a temperature $200-350^{\circ} \mathrm{C}$, and $490 \mathrm{~nm}$ emission at $125-175^{\circ} \mathrm{C}$. There is peak with low intensity at $600 \mathrm{~nm}$. The UV emission band is absent in TL spectra of HD2-57. 
nealing prior irradiation could significantly increase the luminescence sensitivity, typically by three orders. Poolton et al. (2000) explained the OSL sensitivity increase and concluded that $\mathrm{E}^{\prime}$ centres are annealed out of the samples at temperatures in the range $500-700^{\circ} \mathrm{C}$.

Radio-luminescence and thermoluminescence spectra were used by Schilles et al. (2001) as a means of investigating the luminescence sensitivity changes if quartz was heated beyond the first and second crystal phase transitions, in the temperature range 573 and $1050^{\circ} \mathrm{C}$. The results lead them to conclude that luminescence is generally sensitised in quartz by removal of oxygen vacancy $E$, centres, which act either as non-radiative recombination centres or as luminescence centres emitting in the deep UV-region. They concluded that after annealing material beyond the first phase transition, the UV $(360 \mathrm{~nm})$ emission became enhanced in their samples.

Martini et al. (2009) reported that samples annealed at around $500^{\circ} \mathrm{C}$ showed dramatic enhancement of the $3.4 \mathrm{eV}(360 \mathrm{~nm})$ band followed by a decrease. This is consistent with our observation for quartz HD3 which exhibits similar TL spectra suggesting that quartz experienced in the past the annealing around the first transition phase. Deconvolution into Gaussian components of the thermoluminescence emission spectra of HD3 indicates the presence of $363 \mathrm{~nm}$ band.

Further, Martini et al. (2012) showed that "hydrogenswept" quartz has no UV emission. Hydrogen is important due to the supposed participation in various generation processes of defects, both intrinsic and extrinsic, and to the high mobility. Hashimoto et al. (2001) reported that the atomic hydrogen derived from the radiolysis of OH-related impurities could operate as a "killer" of radiation-induced $\mathrm{Al}$-centers.

The study of the relationship between the luminescence emissions and specific defects in quartz is beyond the scope of this study. However, it can be inferred that the technological parameters of manufacturing grey coloured bricks, including high-temperature annealing and cooling using hydrogen reduction, could have affected luminescence properties such as the decrease in the UV emission band.

In the following sections, we addressed the question of whether the TL spectra affect luminescence properties and the dose assessment using different SAR measurements.

\section{OSL characteristics of quartz}

In OSL dating protocols, OSL signal is usually obtained under during optical stimulation at steady stimulation power, resulting in a continuous wave OSL $(\mathrm{CW}$ OSL) signal. It is well-known that the decay of signal during the OSL measurement of quartz does not form the simple exponential, it is composed of components generally referred to as fast, medium and slow, each of which has different optical and thermal luminescence properties, indicating the existence of three optically active traps according to Bailey et al. (1997).

Alternatively, the OSL signal measured using a linearly increasing stimulation power to obtain the linearly modulated OSL (LM-OSL, (Bulur, 1996)) signal tends to separate the individual OSL components involved in the OSL production, and it was initially used as an analytical tool (Bulur et al., 2000, 2002) for discriminating the different OSL components (Jain et al., 2003), (Singarayer and Bailey, 2003).

Representative blue-stimulated CW-OSL decay curves of heated quartz are shown in Fig. 3. Note that $\mathrm{HD} 3$ was stimulated for $20 \mathrm{~s}$ after preheating at $220^{\circ} \mathrm{C}$, $\mathrm{HD} 2-57$ for $100 \mathrm{~s}$ after preheating at $260^{\circ} \mathrm{C}$. The test dose CW-OSL signal was fitted to a sum of first-order exponential components, and the fitting procedure revealed that the OSL signal of HD3 comprised the dominant fast component. The contribution of fast, medium and slow components are shown in the inset. In contrast, HD2-57 does not have a fast OSL component, but medium and slow components.

A simple mathematical transformation to convert the CW-OSL decay curves to the LM-OSL curves was performed according to Bulur (2000), and pseudo-LM-OSL curves constructed are shown in Fig. 3b, 3d for quartz HD3 and HD2-57, correspondingly. The inset shows the relative contribution of fast, medium and slow components derived from the pseudo-LM-OSL.

The fitting of multi-exponential functions to the CWOSL decay curves from HD3 revealed the presence of fast, medium and slow OSL components correspondingly. The corresponding photoionisation cross-sections values were $2.47 \pm 0.33 \times 10^{-17} \mathrm{~cm}^{2}$ (fast), $5.05 \pm 1.44 \times 10^{-18} \mathrm{~cm}^{2}$ (medium), which are in agreement with the values of $2.32 \pm 0.16 \times 10^{-17} \mathrm{~cm}^{2}$ and $5.59 \pm 0.44 \times 10^{-18} \mathrm{~cm}^{2}$ (Jain et al., 2003).

The fitting procedure revealed that the LM-OSL signal of HD3 (Fig. 3e) is dominated by fast, and LM-OSL of $\mathrm{K} 02 / 02$ is not dominated by fast OSL component, but by the medium and slower components, these results are consistent with the CW-OSL results. The corresponding photoionisation cross sections for fast, medium and slow components were $2.15 \times 10^{-17}, 3.14 \times 10^{-18}, 4.64 \times 10^{-19}$ $\left(\mathrm{cm}^{2}\right)$, respectively, giving rise to $\mathrm{b}$ values of $1.59,0.52$ and $0.04\left(\mathrm{~s}^{-1}\right)$, which is in agreement with (Choi et al., 2006).

\section{Application of SAR}

\section{CW-OSL}

The single-aliquot regenerative dose protocol based on the measurement of optically stimulated luminescence from heated ceramics has been successfully used in retrospective dosimetry (Bøtter-Jensen et al., 2000) and for dating of heated ceramics in archaeology and art history (Bailiff, 2007; Chruścińska et al., 2014; Solongo et al., 2014; Solongo et al., 2006a). Here we present SAR 

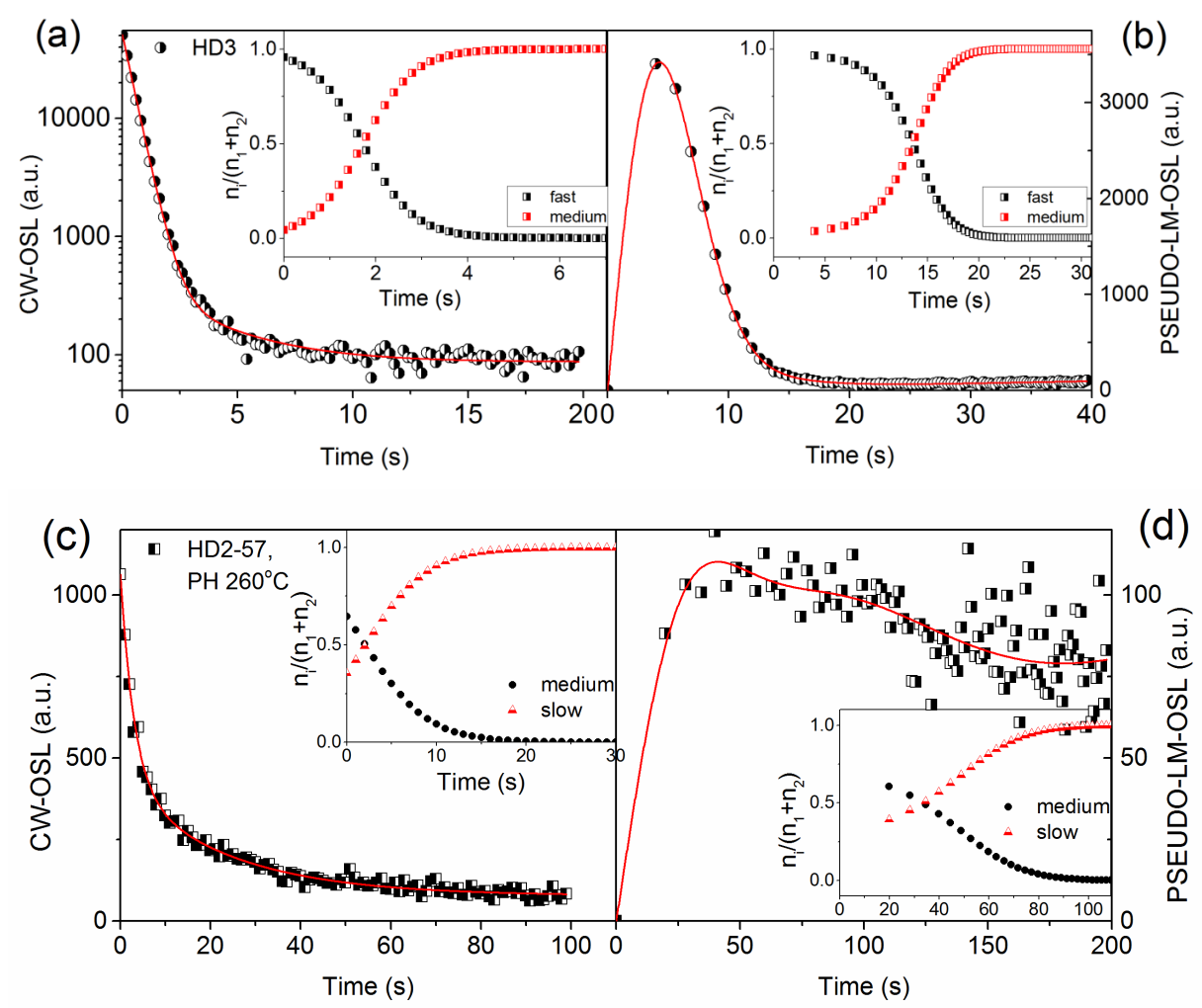

(e)
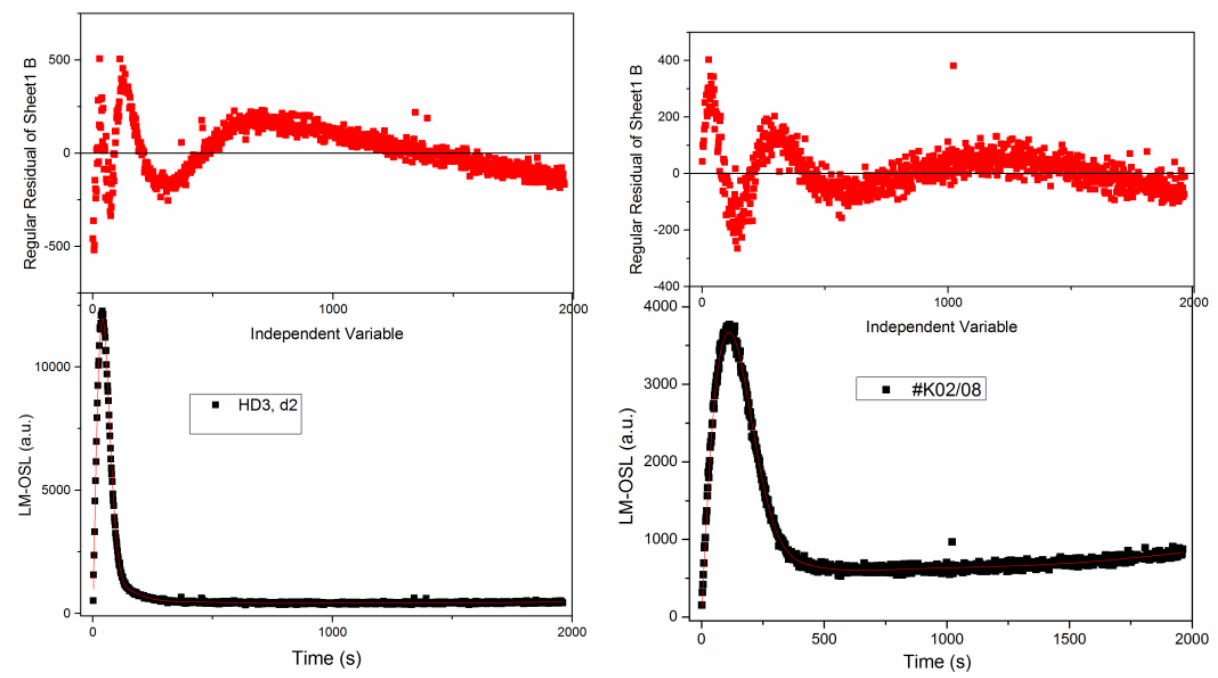

Fig. 3. (a, b) Fitting of CW-OSL decay curves and (c, d) pseudo-LM-OSL decay curves for quartz HD3 and HD2-57. The insets show the relative contribution of fast and medium components. (e) Deconvolution of experimental LM-OSL curves HD3 and K02-08.

measurements using CW-OSL (Table 2) performed on HD3 and K02/08. Figs. 4a, 4b show the representative natural, regenerated and test dose CW-OSL decay curves recorded during the SAR cycles, respectively. The signal is derived from the initial three channels of the CW-OSL minus background.

There are several main features in the CW-OSL signals recorded during SAR:
1) OSL signals of HD3 are bright. Test dose-response of $\mathrm{HD} 3$ to a test dose $\mathrm{TD}=2 \mathrm{~s}$ (or $174 \mathrm{mGy}$ ) is $\sim 8,000$ cts in the initial $0.2 \mathrm{~s}$ of stimulation; recycling ratio $\left(R_{5} / R_{1}\right)$ is 1.0 . The recuperated signal $\left(R_{4}\right)$ implicated by the ratio of the sensitivity-corrected 0 Gy value to the sensitivity-corrected natural signal is small ( $\sim 100$ counts, $\mathrm{R}_{4} / \mathrm{N}$ is 0.1$)$. The OSL signal 

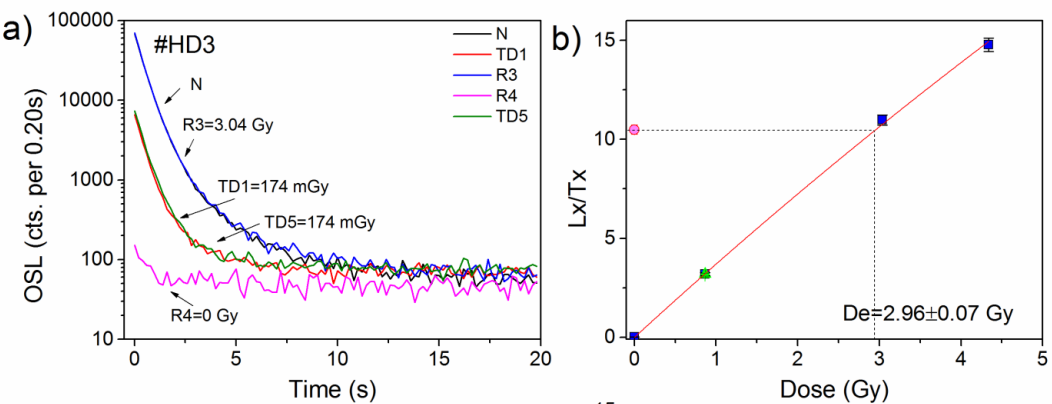

Fig. 4. (a), (c) The representative natural, regenerated and test dose CW-OSL decay curves recorded during the SAR cycles for quartz HD3 and K02/08, respectively, $N$-natural OSL, $R 3, R 4$ - regenerated OSL, TD1,TD5 - test dose OSL. (b), (d) The corresponding dose-response curve fitted by exponential fit.

c)
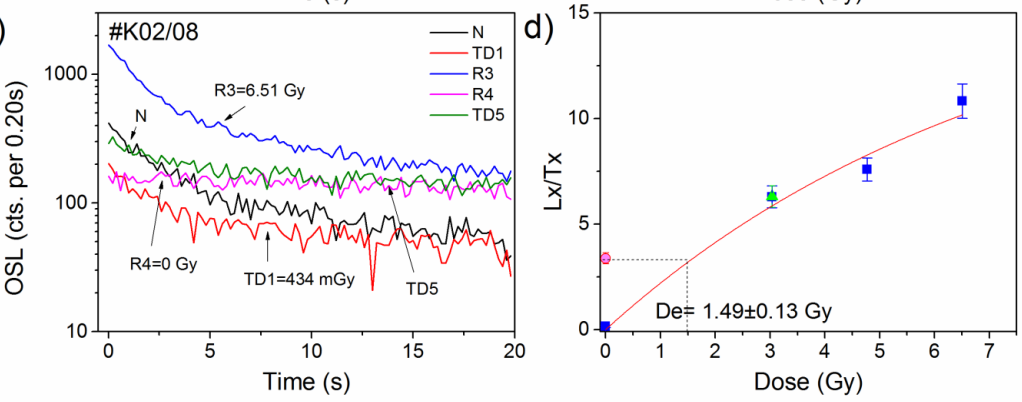

is dominated by the fast component (Fig. 3), and the ratio of fast to medium was 12 . The corresponding dose-response curves were fitted by exponential, from which the equivalent dose of $2.96 \pm 0.07$ Gy was derived for HD3.

2) OSL signals of $\mathrm{K} 02 / 08$ are very dim. Test doseresponse of $\mathrm{K} 02 / 08$ to a test dose $\mathrm{TD}=4 \mathrm{~s}$ (or $344 \mathrm{mGy}$ ) is $\sim 150$ cts. per $0.2 \mathrm{~s}$; recycling $<10 \%$. The recuperated signal $\mathrm{R}_{4}$ is $\sim 100$ cts., that makes $4.5 \%$ of natural OSL. The OSL signal, fitted by a sum of two exponentials, the fast ratio is only 0.6 and the equivalent dose of $1.49 \pm 0.13$ Gy for K02/08 was derived.

For that sample K02/08, additionally, a preheat temperature plateau test was conducted, this is done order to select appropriate preheat conditions that minimise thermal transfer for $D_{\mathrm{e}}$ determination using the SAR protocol. Preheat temperatures from $200^{\circ} \mathrm{C}$ to $280^{\circ} \mathrm{C}$ with an interval of $20^{\circ} \mathrm{C}$ were tested, with the cut-heat kept at 200 to $220^{\circ} \mathrm{C}$ for $10 \mathrm{~s}$, using the heating rate of $5^{\circ} \mathrm{C} / \mathrm{s}$. Three aliquots were used for each temperature point, and the corresponding dose-response plots of the three aliquots for each preheat are shown in Fig. 5. A plateau was observed for temperatures from $200^{\circ} \mathrm{C}$ to $240^{\circ} \mathrm{C}$, which is recommended to select for routine $D_{\mathrm{e}}$ determination.

To see how the preheat temperature affects the TL glow curve, we performed an additional sequence at the end of SAR: give a dose of $1.1 \mathrm{~Gy}$ and measure TL without preheating. Fig. 5b shows these TL glow curves registered at the end of the SAR cycle. Interesting here is the relationship between the OSL and TL measurements. At higher preheats, the OSL intensity increases and the slope of growth curves (Lx/Tx) become flatter as the test dose (Tx) OSL increases; this sensitivity increase of TL $110^{\circ} \mathrm{C}$ signal in the TL glow curves may be the indicator of such increase. The $\mathrm{D}_{\mathrm{e}}$ 's obtained for the preheat temperature of $260^{\circ} \mathrm{C}$ are higher. However, sensitivity changes that occur during the SAR cycles starting at $240^{\circ} \mathrm{C}$ preheat become too high $(>2)$.

\section{LM-OSL}

The first successful attempt with LM-OSL using SAR protocol was made ( $\mathrm{Li}$ and $\mathrm{Li}, 2006)$ and Choi et al. (2006) on coarse-grain quartz extracted from sediments. However, it has not been widely adopted because of the greater time required to make the LM-OSL measurements and the extra time needed for analysis compared with using CW-OSL (Wintle and Adamiec, 2017).

We adopted LM-OSL using SAR protocol (Table 2), which includes an additional step 7, namely, repeated readings of $\mathrm{LM}-\mathrm{OSL}$ at $125^{\circ} \mathrm{C}$, with no heating between the measurements; this was done to ensure that the hardto-bleach component was optically bleached (Bulur et al., 2002). Examples of LM-OSL glow curves for brick samples HD3 and K02/02 are shown in Fig. 6. LM-OSL peak has two important parameters, the peak height, $L_{\max }$, and the peak position on the time scale $t_{\text {max }}$.

For HD3, LM-OSL measurement time was $3000 \mathrm{~s}$; the natural and regenerated LM-OSL signals recorded during SAR and test dose-response to a test dose $\mathrm{TD}=3 \mathrm{~s}$ (or $260 \mathrm{mGy}$ ) are shown in Fig. 6b. The fitting procedure showed that the OSL signal is dominated by the fast component. The equivalent dose will be estimated using dose-response, integrating the fast component (0-200 s) and the slow component (last $100 \mathrm{~s}$ ), from which a dose of $3.5 \pm 0.1$ Gy was derived. This is in agreement with those obtained using the initial part of the CW-OSL de- 

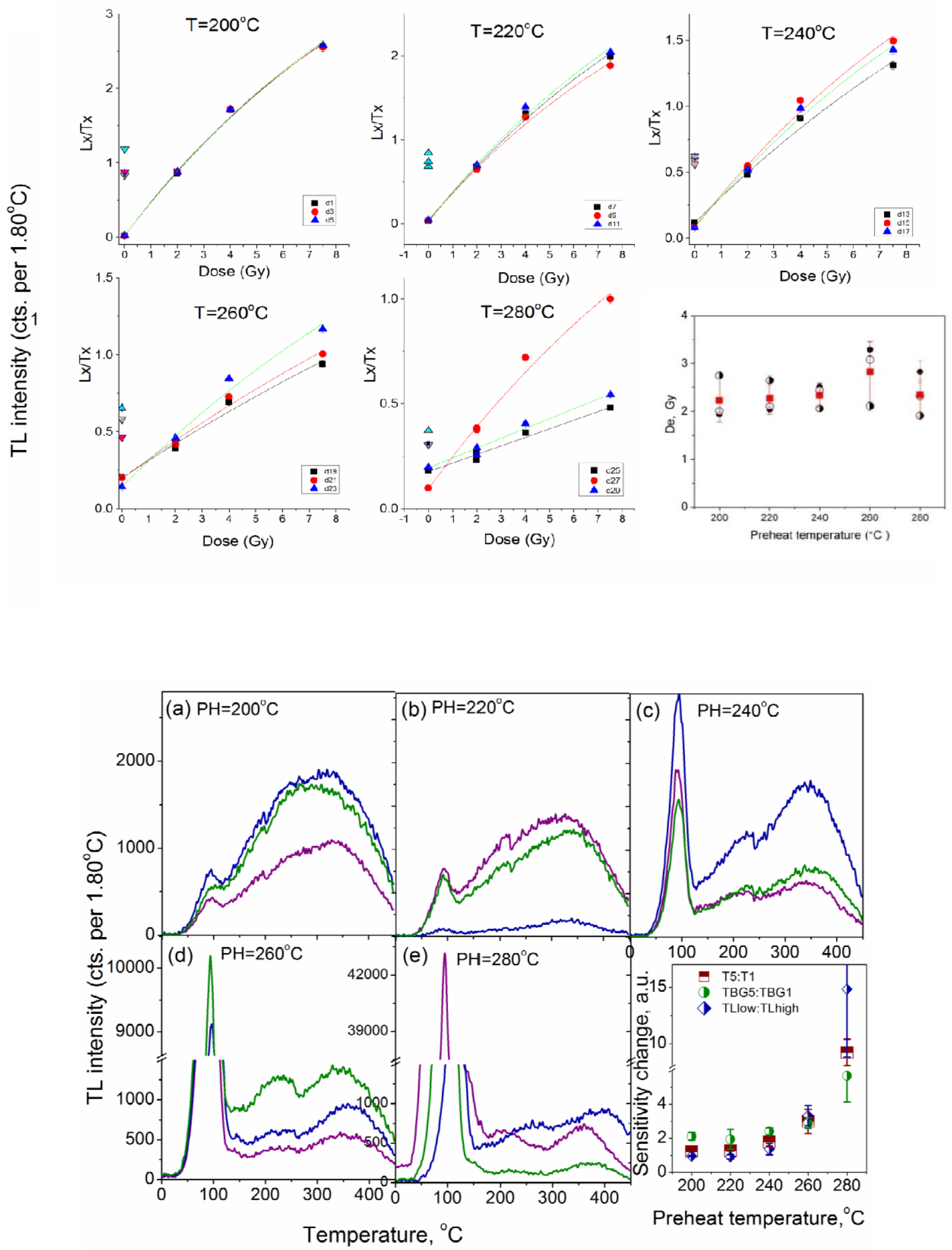

Fig. 5. Preheat plateau test K02/08. a) dose-response curves obtained for preheat temperatures from $200^{\circ} \mathrm{C}$ to $280^{\circ} \mathrm{C}$ and the corresponding preheat plot $D_{e}=f(T)$. b) TL glow curves obtained at the end of SAR protocol after giving a dose of $1.1 \mathrm{~Gy}$. Inset shows sensitivity changes occurring during SAR. 

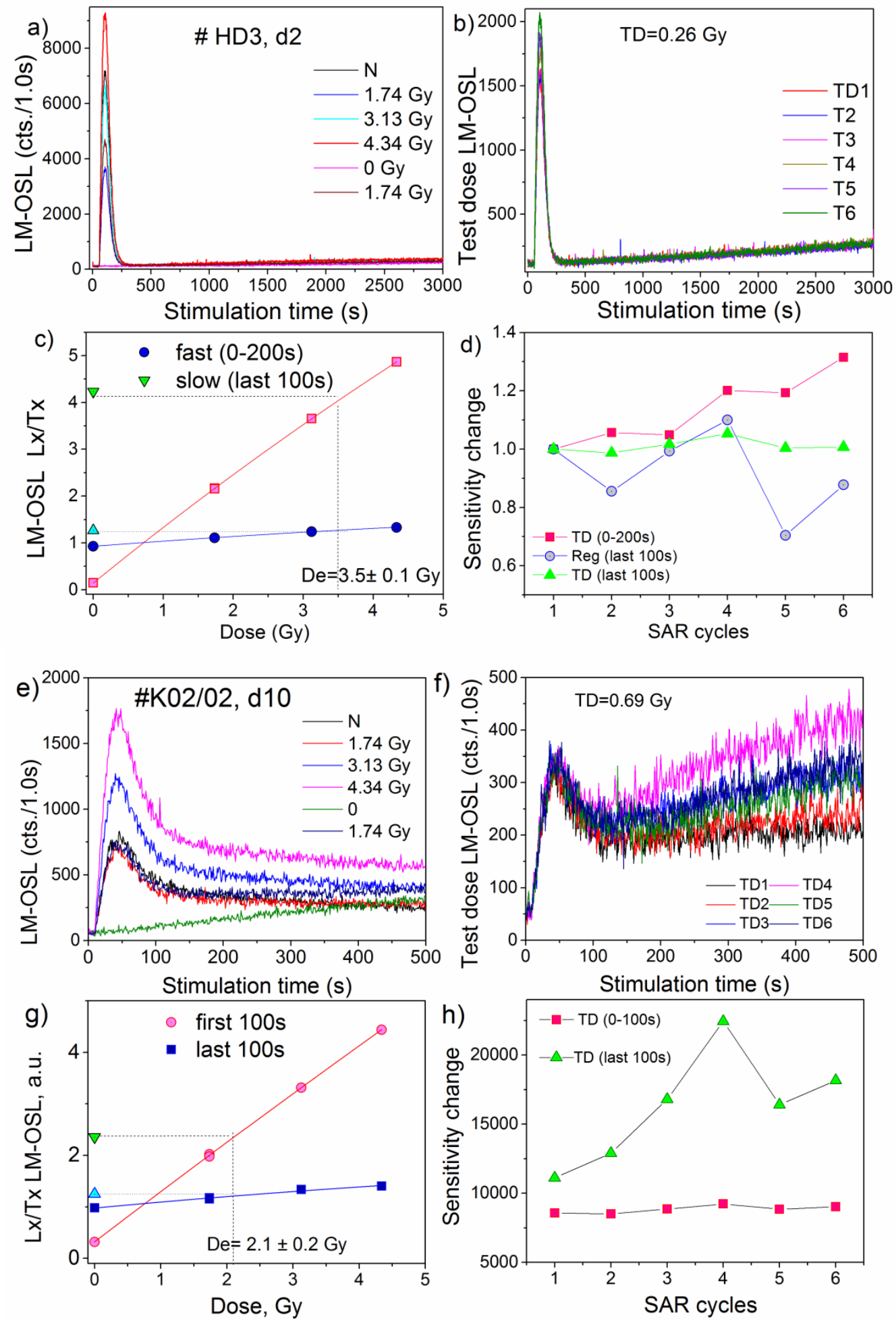

Fig. 6. LM-OSL measurements on HD3 and K02-02 using SAR. (a, e) The natural $(N)$ and regenerated (Reg) LM-OSL curves; (b, $f$ ) test dose LMOSL; (c) LM-OSL dose-response curve derived by integrating fast (0-200 s) and slow (last $100 \mathrm{~s}$ ) for HD3 and by integrating medium (0-100 s) and slow (last 100 s) for K02-02; (d) The sensitivity changes occurring during SAR cycles. Test dose TD - signal (0-200 s), Reg and TD signals of slow components derived as integer of last $100 \mathrm{~s}$. 
cay curve. The sensitivity changes of fast $(0-200 \mathrm{~s})$ and slow (last $100 \mathrm{~s}$ ) components during the SAR cycles are shown in Fig. 6d.

For quartz K02-02, LM-OSL measurements were conducted for $\mathrm{t}=500 \mathrm{~s}$. Figs. 6e, 6f show the natural, regenerated and test dose curves. The dose-response plot was constructed using the integrating $0-100 \mathrm{~s}$, from which a dose of $2.1 \pm 0.2$ Gy was derived, which was probably based not on the fast OSL component. It is observed that the OSL signal derived from the last $100 \mathrm{~s}$ of measurement of the test dose, possibly due to the hardto-bleach slower components, increases with each SAR cycle (see Fig. 6h). This observation is consistent with results published elsewhere that in some samples sensitisation of slow components with heating can occur at a much higher rate than of the fast/medium components.

The fitting LM-OSL curve with a sum of relevant components is difficult and time-consuming; therefore, instead of applying curve fitting, the equivalent dose may be determined using a dose-response from integrating 0 $100 \mathrm{~s}$ signal. Furthermore, the equivalent dose obtained was in agreement with those obtained using the initial part of the CW-OSL.

\section{$T L-S A R$}

TL dating is usually used to the dating of bricks (Bailiff and Holland, 2000; Blain et al., 2007; Chruścińska et al., 2008, 2014; Guibert et al., 2009; Martini and Sibilia, 2001; Solongo et al., 2014). Two methods were used to determine $D_{e}-T L$ measurements using SAR (Table 2) and the TL-REG (regenerative measurements involved the same sequence as TL-SAR but without test dose) method. Preheat at $180^{\circ} \mathrm{C}$ was used, and the TL glow curves $\left(180-495^{\circ} \mathrm{C} ; 5^{\circ} \mathrm{C} / \mathrm{s}\right)$ were registered. The ratio of natural TL to laboratory regenerated TL signal (NatTL/RegTL) versus temperature was plotted for each aliquot; the integration range was 325 $370^{\circ} \mathrm{C}$ (or $300-350^{\circ} \mathrm{C}$ ). Examples of TL glow curves for brick samples K02/08 K02/36 are shown in Fig. 7. Inset in Fig. 7b shows the sensitivity changes during the SAR cycles. There is no difference between the TL-SAR and TL-REG for these samples; SAR TL $D_{e}$ is $3.81 \pm 0.33$ $(\mathrm{n}=10)$ and using TL-REG $\mathrm{D}_{\mathrm{e}}$ of $3.5 \pm 0.20 \mathrm{~Gy}$.

\section{Luminescence ages}

The overall goal of this study was to evaluate the potential of luminescence dating as a tool for building archaeology. The results obtained by OSL and TL for all samples under study are summarised in Table 3. As can be seen from Table there is an agreement between the OSL and TL data for red-coloured brick samples originated from the Great hall basement (\#K02/01, HD12B, Hd3 and HD3-1); furthermore, all results are consistent with the age control in the form of the Karakorum inscription 1346. Brick sample (B288B) is an only redcoloured sample that yields date of $1370 \pm 55 \mathrm{AD}$, depicting the basement in the manufacturing district, all other bricks were grey coloured.
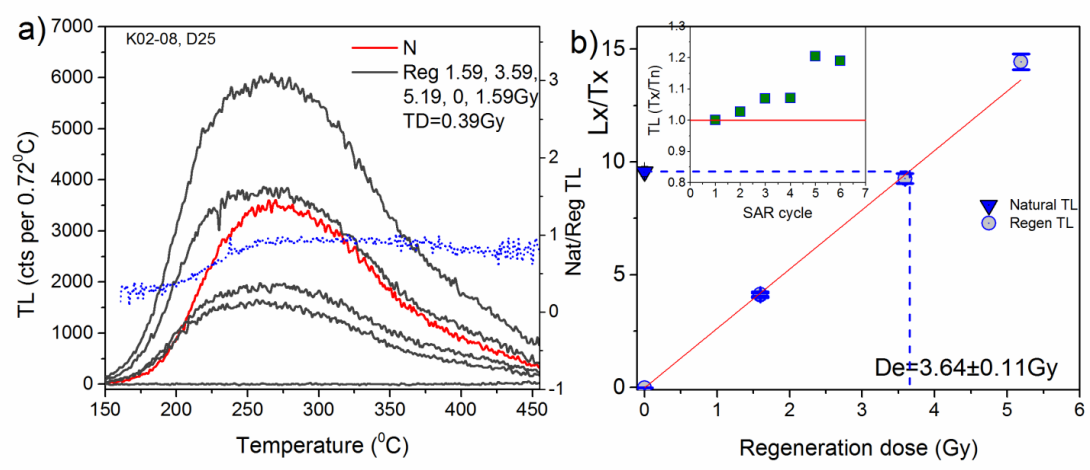

Fig. 7. a) SAR-TL und c) regenerated TL measurements on heated quartz K02/08. TL signal was derived by integrating $325-370^{\circ} \mathrm{C}$ and $300-350^{\circ} \mathrm{C}$, correspondingly. (b, c) corresponding doseresponse curves. Inset in b) shows sensitivity changes during SAR. SAR TL De is $3.81 \pm 0.33 \mathrm{~Gy}$ $(n=10)$. Regenerated TL gives De of $3.5 \pm 0.20 \mathrm{~Gy}$.

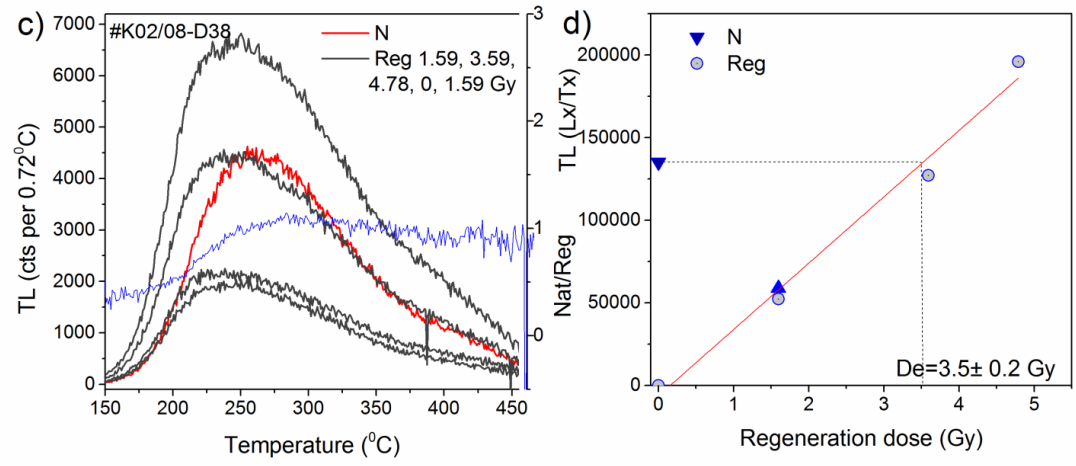


Table 3. Age estimates and dose $D_{e}$ obtained using different luminescence methods (n number of aliquots, all doses are obtained for coarse quartz). ${ }^{*}$ CW-OSL dates were taken from Solongo et al. (2006a).

\begin{tabular}{|c|c|c|c|c|c|}
\hline Sample description & Method & $\mathrm{N}$ aliqouts & $\begin{array}{c}D_{e} \\
(G y)\end{array}$ & $\begin{array}{c}D_{r} \\
\text { (Gy/ka) }\end{array}$ & $\begin{array}{l}\text { Date } \\
\text { (AD) }\end{array}$ \\
\hline \multirow{3}{*}{ K02/01, brick, Great Hall floor, red colored } & CW-OSL* & 12 & $3.16 \pm 0.07$ & \multirow{3}{*}{$4.56 \pm 0.32$} & $1310 \pm 45$ \\
\hline & LM-OSL & 3 & $2.90 \pm 0.10$ & & $1370 \pm 50$ \\
\hline & TL-SAR & 6 & $3.48 \pm 0.09$ & & $1250 \pm 55$ \\
\hline \multirow{2}{*}{ HD12B, brick, Great Hall basement, red colored } & CW-OSL & 24 & $2.90 \pm 0.09$ & \multirow{2}{*}{$4.58 \pm 0.30$} & $1340 \pm 45$ \\
\hline & LM-OSL & 3 & $2.98 \pm 0.07$ & & $1350 \pm 45$ \\
\hline \multirow{2}{*}{ HD3, brick, red colored, Great Hall area } & CW-OSL & 24 & $3.07 \pm 0.06$ & \multirow{2}{*}{$4.61 \pm 0.28$} & $1340 \pm 40$ \\
\hline & LM-OSL & 4 & $3.20 \pm 0.10$ & & $1310 \pm 50$ \\
\hline \multirow{2}{*}{ HD3-1, brick, red-colored, Great Hall area } & CW-OSL & 44 & $3.28 \pm 0.04$ & \multirow{2}{*}{$4.60 \pm 0.29$} & $1290 \pm 40$ \\
\hline & LM-OSL & 10 & $3.00 \pm 0.10$ & & $1345 \pm 55$ \\
\hline \multirow{2}{*}{ B288B brick, red-colored, basement, manufacturing quarter } & CW-OSL & 21 & $3.30 \pm 0.14$ & \multirow{2}{*}{$5.19 \pm 0.31$} & $1370 \pm 55$ \\
\hline & LM-OSL & 3 & $2.90 \pm 0.10$ & & $1450 \pm 50$ \\
\hline \multirow{2}{*}{ HD2/57, grey colored, Great Hall area } & CW-OSL & 6 & - & \multirow{2}{*}{$4.43 \pm 0.30$} & - \\
\hline & TL reg & 6 & $2.89 \pm 0.17$ & & $1360 \pm 70$ \\
\hline \multirow{4}{*}{ K02/08 wall brick, stupa basement, grey colored HD12 } & CW-OSL* & 14 & $1.90 \pm 0.33$ & \multirow{4}{*}{$4.87 \pm 0.28$} & $1610 \pm 70$ \\
\hline & LM-OSL & 2 & $1.90 \pm 0.25$ & & $1620 \pm 60$ \\
\hline & TL-SAR & 10 & $3.81 \pm 0.33$ & & $1220 \pm 85$ \\
\hline & TL-REG & 6 & $3.65 \pm 0.23$ & & $1260 \pm 70$ \\
\hline \multirow{3}{*}{ K02/02, brick, Buddhist Lotus trone, grey colored } & CW-OSL & 10 & $2.08 \pm 0.32$ & \multirow{3}{*}{$4.7 \pm 0.28$} & $1560 \pm 80$ \\
\hline & LM-OSL & 2 & $2.10 \pm 0.20$ & & $1560 \pm 50$ \\
\hline & TL-SAR & 6 & $3.63 \pm 0.30$ & & $1340 \pm 80$ \\
\hline \multirow{2}{*}{ K36, brick, small kiln, grey colored } & CW-OSL & 12 & $2.18 \pm 0.51$ & \multirow{2}{*}{$4.87 \pm 0.29$} & $1560 \pm 120$ \\
\hline & TL-SAR & 6 & $4.10 \pm 0.05$ & & $1190 \pm 70$ \\
\hline
\end{tabular}

On the contrary, the $\mathrm{D}_{\mathrm{e}}$ results obtained by TL SAR protocol for grey coloured samples (K02-08, K02-02, K02-36) are higher than those obtained by OSL. For sample K02-02 and K02-08, which are taken from the basement of historical buildings such as Buddhist stupa and lotus, the TL dates correlate with the time of constructing the Buddhist stupa that is known from historical documentary records.

\section{CONCLUSIONS}

In this study, we presented results of CW-OSL, LMOSL and TL using SAR protocols on heated quartz from the archaeological and historical site in the Karakorum (1220/1235-1260/1370-1388) - the ancient capital of Mongolia, to test their convergence with the age control in the form of the Karakorum inscription 1346. The old Mongolian capital of Karakorum was moreover a centre of great importance for manufacturing, which has been documented by the kilns, that show that not only bricks and roof tiles were fabricated on-site but also building decorations, clay sculptures and the thousands of Tsa-tsa were deposited in the hall. A series of bricks were selected based on the need for chronological evaluation of the Great Hall building.

The TL spectra conducted on quartz from red and grey coloured bricks appeared to be characteristic of the technological origin. Quartz TL from red bricks showed a UV emission band at $\sim 360 \mathrm{~nm}$ and a strong fast OSL component dominated signal. In contrast, blue emission detected in the TL spectra of grey coloured bricks, resulting possibly in the medium component dominated OSL signal. Quartz TL from red bricks showed intense UV emission band at $\sim 360 \mathrm{~nm}$; this is consistent with previous findings (Bøtter-Jensen et al., 1995) that annealing at around $500^{\circ} \mathrm{C}$ showed dramatic enhancement associated with intense OSL emission. Both CW-OSL and LM-OSL signals are dominated by fast component, and the sensitivity changes and recuperation of fast component are negligible. Doses obtained using CW-OSL, LM-OSL and TL protocols on red-coloured bricks gave ages in reasonably good agreement with each other and with the historical age.

On the contrary, it can be inferred that the technological parameters of manufacturing grey coloured bricks, including high-temperature annealing and cooling using hydrogen reduction, could have affected luminescence properties such as the decrease in the UV emission band. Therefore, quartz from grey-colored bricks is assigned to the low intensity OSL signal, dominated by medium OSL component. Both, CW-OSL and LM-OSL measurements using SAR protocols resulted in younger ages, probably from the medium OSL component. However, TL results gave dates from $1180 \pm 70 \mathrm{AD}$ to $1360 \pm 70$ consistent with the historically expected ages. 


\section{ACKNOWLEDGEMENTS}

Saran Solongo acknowledges the financial support of TWAS research grants 17-521RG/PHYS/AS_GFR320300144 and SS 2017/63 from the Science and Technology Foundation of Mongolia. This work was initiated during a DFG (German Research Foundation) fellowship to Saran Solongo, who thanks Luminescence Laboratory at the MPI Heidelberg for providing access to luminescence facilities. We thank two reviewers for their helpful comments on an earlier version of the manuscript, which improved it significantly.

\section{REFERENCES}

Bailey RM, Smith BW and Rhodes EJ, 1997. Partial bleaching and the decay form characteristics of quartz OSL. Radiation Measurements 27: 123-136, DOI 10.1016/S1350-4487(96)00157-6.

Bailiff IK, 2007. Methodological developments in the luminescence dating of brick from English late-medieval and post-medieval buildings. Archaeometry 49: 827-851, DOI 10.1111/j.14754754.2007.00338.x.

Bailiff IK and Holland N, 2000. Dating bricks of the last two millennia from Newcastle upon Tyne: a preliminary study. Radiation Measurements 32: 615-619, DOI 10.1016/S1350-4487(99)00286-3.

Banerjee D, Murray AS, Bøtter-Jensen L, Lang A, 2001. Equivalent dose estimation using a single aliquot of polymineral fine grains. Radiation Measurements 33: 73-94, DOI 10.1016/S13504487(00)00101-3.

Blain S, Guibert P, Bouvier A, Vieillevigne E, Bechtel F, Sapin C and Baylé M, 2007. TL-dating applied to building archaeology: The case of the medieval church Notre-Dame-Sous-Terre (Mont-SaintMichel, France). Radiation Measurements 42: 1483-1491, DOI 10.1016/j.radmeas.2007.07.015.

Bøtter-Jensen L, Agersnap Larsen N, Mejdahl V, Poolton NRJ, Morris MF and McKeever SWS, 1995. Luminescence sensitivity changes in quartz as a result of annealing. Radiation Measurements 24: 535-541, DOI 10.1016/1350-4487(95)00006-Z.

Bøtter-Jensen L, Solongo S, Murray AS, Banerjee D, Jungner H, 2000. Using the OSL single-aliquot regenerative-dose protocol with quartz extracted from building materials in retrospective dosimetry. Radiation Measurements 32: 841-845, DOI 10.1016/S13504487(99)00278-4.

Bøtter-Jensen L, Thomsen KJ, Jain M, 2010. Review of optically stimulated luminescence (OSL) instrumental developments for retrospective dosimetry. Radiation Measurements 45: 253-257, DOI 10.1016/j.radmeas.2009.11.030.

Bulur E, 1996. An alternative technique for optically stimulated luminescence (OSL) experiment. Radiation Measurements 26: 701709, DOI 10.1016/S1350-4487(97)82884-3.

Bulur E, 2000. A simple transformation for converting CW-OSL curves to LM-OSL curves. Radiation Measurements 32: 141-145, DOI 10.1016/S1350-4487(99)00247-4.

Bulur E, Bøtter-Jensen L and Murray AS, 2000. Optically stimulated luminescence from quartz measured using the linear modulation technique. Radiation Measurements 32: 407-411, DOI 10.1016/S1350-4487(00)00115-3.

Bulur E, Duller GAT, Solongo S, Bøtter-Jensen L and Murray AS, 2002. LM-OSL from single grains of quartz: a preliminary study. Radiation Measurements 35: 79-85, DOI 10.1016/S13504487(01)00256-6.

Choi JH, Duller GAT, Wintle AG and Cheong CS, 2006. Luminescence characteristics of quartz from the Southern Kenyan Rift Valley: Dose estimation using LM-OSL SAR. Radiation Measurements 41: 847-854, DOI 10.1016/j.radmeas.2006.05.003.
Chruścińska A, Cicha A and Kijek N, 2014. Luminescence dating of bricks from the gothic Saint James Church in Torun. Geochronometria 41: 352-360, DOI 10.2478/s13386-013-0165-y.

Chruścińska J, Jesionowski B, Oczkowski H and Przegiętka K, 2008. Using the tl single-aliquot regenerative-dose protocol for the verification of the chronology of the teutonic order castle in malbork. Geochronometria 30: 61-67, DOI 10.2478/v10003-008-0006-9.

Guerin G, Mercier N and Adamiec G, 2011. Dose-rate conversion factors: update. Ancient TL 29: 5-8.

Guibert P, Bailiff IK, Blain S, Gueli AM, Martini M, Sibilia E, Stella G, Troja SO, 2009. Luminescence dating of architectural ceramics from an early medieval abbey: The St Philbert Intercomparison (Loire Atlantique, France). Radiation Measurements 44: 488-493, DOI 10.1016/j.radmeas.2009.06.006.

Hashimoto T, Fujita H and Hase H, 2001. Effects of atomic hydrogen and annealing temperatures on some radiation-induced phenomena in differently originated quartz. Radiation Measurements 33: 431437, DOI 10.1016/S1350-4487(00)00140-2.

Huntley DJ, Godfrey-Smith DI and Haskell EH, 1991. Light-induced emission spectra from some quartz and feldspars. Nuclear Tracks and Radiation Measurements 18: 127-131.

Hüttel HG and Erdenebat U, 2011. Karabalgasun and Karakorum. Two late nomadic urban settlements in the Orkhon Valley, Ulaanbaatar.

Jain M, Murray AS and Bøtter-Jensen L, 2003. Characterisation of bluelight stimulated luminescence components in different quartz samples: implications for dose measurement. Radiation Measurements 37: 441-449, DOI 10.1016/S1350-4487(03)00052-0.

Jain M, Murray AS and Bwtter-Jensen L, 2003. Characterisation of blue-light stimulated luminescence components in different quartz samples: implications for dose measurement. Radiation Measurements 37: 441-449, DOI 10.1016/S1350-4487(03)00052-0.

Kiselev SV, Evtjuchova LA, Kyzlasov LR, Merpert N Ia and LevashovaVP, 1965. Drevnemongol'skie goroda, Moscow.

Krbetscheck MR, Goetze J, Dietrich A and Trautman T, 1997. Spectral information from minerals relevant for luminescence dating. Radiation Measurements 27: 695-748, DOI 10.1016/S13504487(97)00223-0.

Li S-H and Li B, 2006. Dose measurement using the fast component of LM-OSL signals from quartz. Radiation Measurements 41: 534 541, DOI 10.1016/j.radmeas.2005.04.029.

Martini M, Paleari A, Spinolo G and Vedda A, 1995. Role of [AlO4]0 centers in the 380-nm thermoluminescence of quartz. Physical Review B 52: 138-142, DOI 10.1103/PhysRevB.52.138.

Martini M, Fasoli M and Galli A, 2009. Quartz OSL emission spectra and the role of $[\mathrm{AlO} 4]^{\circ}$ recombination centres. Radiation Measurements 44: 458-461 DOI 10.1016/j.radmeas.2009.04.001.

Martini M, Fasoli M, Villa I and Guibert P, 2012. Radioluminescence of synthetic and natural quartz. Radiation Measurements 47: 846-850 DOI 10.1016/j.radmeas.2012.01.008.

Martini M and Sibilia E, 2001. Radiation in archaeometry: archaeological dating. Radiation Physics and Chemistry 61: 241-246 DOI 10.1016/S0969-806X(01)00247-X.

Murray AS and Wintle AG, 2003. The single aliquot regenerative dose protocol: potential for improvements in reliability. Radiation Measurements 37: 377-381, DOI 10.1016/S1350-4487(03)00053-2.

Poolton NRJ, Smith GM, Riedi PC, Bulur E, Bøtter-Jensen L, Murray AS and Adrian M, 2000. Luminescence sensitivity changes in natural quartz induced by high temperature annealing: a high frequency EPR and OSL study. Journal of Physics D: Applied Physics 33: 1007-1017, DOI 10.1088/0022-3727/33/8/318.

Prescott JR and Hutton JT, 1994. Cosmic ray contributions to dose rates for luminescence and ESR dating: Large depths and long-term time variations. Radiation Measurements 23. 497-500, DOI 10.1016/1350-4487(94)90086-8.

Rieser U, Krbetschek MR and Stolz W, 1999. CCD-camera based high sensitivity TL/OSL spectrometer. Radiation Measurements 23: 523-528, DOI 10.1016/1350-4487(94)90092-2.

Rink WJ, Rendell H, Marseglia EA, Luff BJ and Townsend PD, 1993. Thermoluminescence spectra of igneous quartz and hydrothermal vein quartz. Physics and Chemistry of Minerals 20: 353-361. 
Rose Kerr NW, 2004. Science and Civilisation in China. Cambridge University Press.

Schilles T, Poolton NRJ, Bulur E, Bøtter-Jensen L, Murray AS, Smith GM, Riedi PC, Wagner GA, 2001. A multi-spectroscopic study of luminescence sensitivity changes in natural quartz induced by high-temperature annealing. Journal of Physics D: Applied Physics 34: 722-731, DOI 10.1088/0022-3727/34/5/310.

Singarayer JS and Bailey RM, 2003. Further investigations of the quartz optically stimulated luminescence components using linear modulation. Radiation Measurements 37: 451-458, DOI 10.1016/S1350-4487(03)00062-3.

Solongo S, Richter D, Tuguldur B and Hublin JJ, 2014. OSL and TL characteristics of fine grain quartz from Mongolian prehistoric pottery used for dating. Geochronometria 41: 15-23, DOI 10.2478/s13386-013-0119-4.
Solongo S, Wagner GA and Galbaatar T, 2006a. The estimation of $D e$ using the fast and medium components in fired quartz from archaeological site Karakorum, Mongolia. Radiation Measurements 41: 1001-1008, DOI 10.1016/j.radmeas.2006.05.023.

Solongo S, Wagner GA and Galbaatar T, 2006b. On the origin of dose distributions in quartz extracted from archaaeological ceramics in Karakorum, Mongolia. Proceedings of the Mongolian Academy of Sciences 181: 3-13.

Solongo S, Wagner GA and Galbaatar T, 2006c. The chronology of the brick manufacturing at Karakorum, Mongolia. Preprints of the IPT 33: 60-64.

Wintle AG and Adamiec G, 2017. Optically stimulated luminescence signals from quartz: A review. Radiation Measurements 98: 1033, DOI 10.1016/j.radmeas.2017.02.003. 